\title{
Manejo de Plantas Daninhas na Cultura da Mandioca ${ }^{1}$
}

\author{
Weed Management in Cassava
}

SILVA, D.V. ${ }^{2}$, SANTOS, J.B. ${ }^{3}$, FERREIRA, E.A. ${ }^{4}$, SILVA, A.A. ${ }^{5}$, FRANÇA, A.C. ${ }^{3}$ e SEDIYAMA, T. ${ }^{5}$

\begin{abstract}
RESUMO - A mandioca (Manihot esculenta) é cultivada em vários países, sendo de grande importância como fonte de energia para alimentação humana e animal e na geração de empregos e renda. No Brasil, apesar de essa cultura apresentar alto potencial produtivo em alguns estudos alcançando valores superiores a $100 \mathrm{t} \mathrm{ha}^{-1}$ de raízes -, a produtividade nacional é baixa, atribuída em grande parte ao manejo inadequado das plantas daninhas. A interferência dessas plantas resulta em competição pelos recursos essenciais, como nutrientes, água e luz. Além disso, o controle realizado de maneira incorreta das plantas daninhas nos mandiocais dificulta outros tratos culturais e aumenta os custos de produção. Nesta revisão são abordados os aspectos relativos ao manejo das plantas daninhas na cultura, descrevendo, de forma detalhada, os principais componentes de interferência. Discute-se, em várias situações, o período crítico de competição. Por fim, são apresentados os principais métodos de controle visando à utilização do manejo integrado como forma sustentável do controle de plantas daninhas nessa cultura.
\end{abstract}

Palavras-chave: Manihot esculenta, interferência, períodos de controle, manejo integrado.

\begin{abstract}
Cassava (Manihot esculenta) is grown in many countries, being of great importance as an energy source for food, generating jobs and income. Although this crop has been proved to

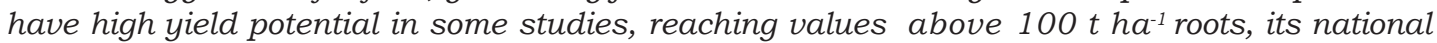
productivity in Brazil is low, being largely attributed to inadequate weed management. The interference of weeds results in competition for essential resources, such as nutrients, water, and light. In addition, incorrectly performed control of weeds in cassava can complicate management and increase production costs. In this review, aspects related to weed management in the culture are described, detailing the main components of interference. The critical period of competition, in many situations, is also discussed. Finally, the main methods of control aimed at the use of integrated management as a sustainable way of controlling weeds in this crop are presented.
\end{abstract}

Keywords: Manihot esculenta, interference, periods of control, integrated management.

\section{INTRODUÇÃO}

Entre todas as culturas, a mandioca (Manihot esculenta) é considerada a de mais alta produtividade de calorias e a de maior eficiência biológica como fonte de energia, além de apresentar boa adaptação a solos deficientes em nutrientes (Nassar, 2006). Nativa do Brasil, sua cadeia produtiva emprega cerca de dois milhões de pessoas. Apesar de apresentar alto potencial produtivo, alcançando em alguns estudos valores superiores a $100 \mathrm{t} \mathrm{ha}^{-1}$, a produtividade nacional é baixa $\left(14,26 \mathrm{t} \mathrm{ha}^{-1}\right)$ (IBGE, 2010). Segundo Albuquerque et al. (2008), o manejo inadequado das plantas daninhas é um dos principais fatores que contribuem para a baixa produtividade da cultura de mandioca no Brasil.

Recebido para publicação em 16.9.2011 e aprovado em 29.4.2012.

2 Eng-ō-Agrōe, M.Sc., Doutorando, Dep. de Fitotecnia, Universidade Federal de Viçosa - DFT/UFV, 36570-000 Viçosa-MG, <danielvaladaos@yahoo.com.br>; 3 Professor Adjunto, Dep. de Agronomia, UFVJM, <barbosa@pq.cnpq.br>, $<$ cabralfranca@yahoo.com.br>; ${ }^{4}$ Engo-Agro-., D.Sc., Bolsista PNPD, UFVJM, Diamantina-MG, <evanderalves@yahoo.com.br>; ${ }^{5}$ Engo-Agro.., D.Sc., Professor Associado, DFT/UFV, <aasilva@ufv.br>, <t.sediyama@ufv.br>. 
Entre as práticas de manejo utilizadas nos mandiocais, o controle de plantas daninhas é muitas vezes negligenciado pelos pequenos produtores por acreditarem que, por ser essa cultura rústica, não precisam se preocupar com o controle. Todavia, entre os fatores bióticos, essas plantas são tidas como um dos principais componentes do agroecossistema da cultura que interferem no desenvolvimento e na produtividade da cultura da mandioca (Albuquerque et al., 2008). O grau de interferência das plantas daninhas depende de fatores ligados à própria cultura, à comunidade infestante, ao ambiente e ao período em que elas convivem (Silva et al., 2007). Segundo Azevedo et al. (2000), a cultura da mandioca possui crescimento inicial lento, o que deixa o solo descoberto, facilitando dessa forma o desenvolvimento de plantas daninhas que competem pelos fatores de produção. A presença dessas plantas na área de cultivo pode resultar em redução no número, na massa seca e no teor de amido de raízes de mandioca.

Nesta revisão procurou-se abordar os aspectos relativos ao manejo das plantas daninhas na cultura da mandioca, descrevendo, de forma detalhada, os principais componentes de interferência. Discute-se também, em várias situações, o período crítico de competição. Por fim, são apresentados os principais métodos de controle visando à utilização do manejo integrado como forma sustentável no controle de plantas daninhas.

\section{Interferência de plantas daninhas na cultura da mandioca}

O cultivo da mandioca pode ter ciclos de menos de um ano quando a finalidade é o consumo in natura ou mais de dois anos quando para a indústria. Em decorrência disso, a cultura está sujeita a vários ciclos de infestação de plantas daninhas. Estas são favorecidas ainda pela arquitetura da copa, pelo espaçamento de cultivo e pelo lento crescimento inicial da mandioca. A intensidade da competição imposta pelas plantas daninhas varia com a duração do período de convivência e estádio da cultura. Manter a cultura livre de quaisquer outras plantas na entrelinha ou mesmo entre plantas pode favorecer a erosão do solo, impedir ciclagem de nutrientes e dificultar o manejo de pragas e doenças, promovendo baixa sustentabilidade à atividade (Silva et al., 2007).

O plantio de mandioca é feito em todo o território brasileiro, sendo as características de cultivo discrepantes em duas grandes regiões do País: centro-sul e norte-nordeste (Peressin \& Carvalho, 2002). A primeira região é caracterizada principalmente pela mecanização no plantio e, em menor escala, da colheita, pelo uso crescente de herbicidas, pela adubação química e pela constante renovação e/ou introdução de cultivares. Já na região norte-nordeste o cultivo da mandioca é realizado sem irrigação, com reduzido manejo do solo e inadequado controle de doenças e de pragas, sendo comum a prática do policultivo.

Em geral, a interferência das plantas daninhas altera o crescimento e o desenvolvimento das plantas de mandioca, causando-lhes redução do tamanho, peso e número de raízes. De acordo com Peressin \& Carvalho (2002), os gastos com controle das plantas daninhas nos mandiocais representam aproximadamente $40 \%$ do custo de produção. Segundo esses autores, não controlar as invasoras pode provocar reduções em até $70 \%$ no rendimento da cultura. Todavia, a magnitude dessa redução depende, entre outros fatores, das espécies infestantes presentes na área.

Levantamentos realizados por diversos autores (Alcantara et al., 1982, 1983; Peressin et al., 1998; Moura, 2000; Azevêdo et al., 2000; Carvalho et al., 2004; Johanns \& Contiero, 2006; Albuquerque et al., 2008; Guglieri et al., 2009; Pinotti et al., 2010; Biffe et al., 2010) identificaram dezenas de espécies de plantas daninhas, de vários gêneros e famílias, infestando mandiocais. Essas espécies variam de acordo com o local, a época de plantio, o manejo e o histórico da área. Na Tabela 1 são apresentados os resultados de trabalhos com períodos de controle e as principais espécies de plantas daninhas encontradas em mandiocais em diferentes locais do Brasil, os quais estão agrupados em duas grandes regiões produtoras. Embora muitas dessas espécies sejam comuns às diversas regiões do País, observa-se que cada Estado e região apresentam suas peculiaridades quanto às espécies de planta daninha predominante. Desse modo, podem-se atribuir as variações na interferência das plantas daninhas à diversidade de situações nas quais 


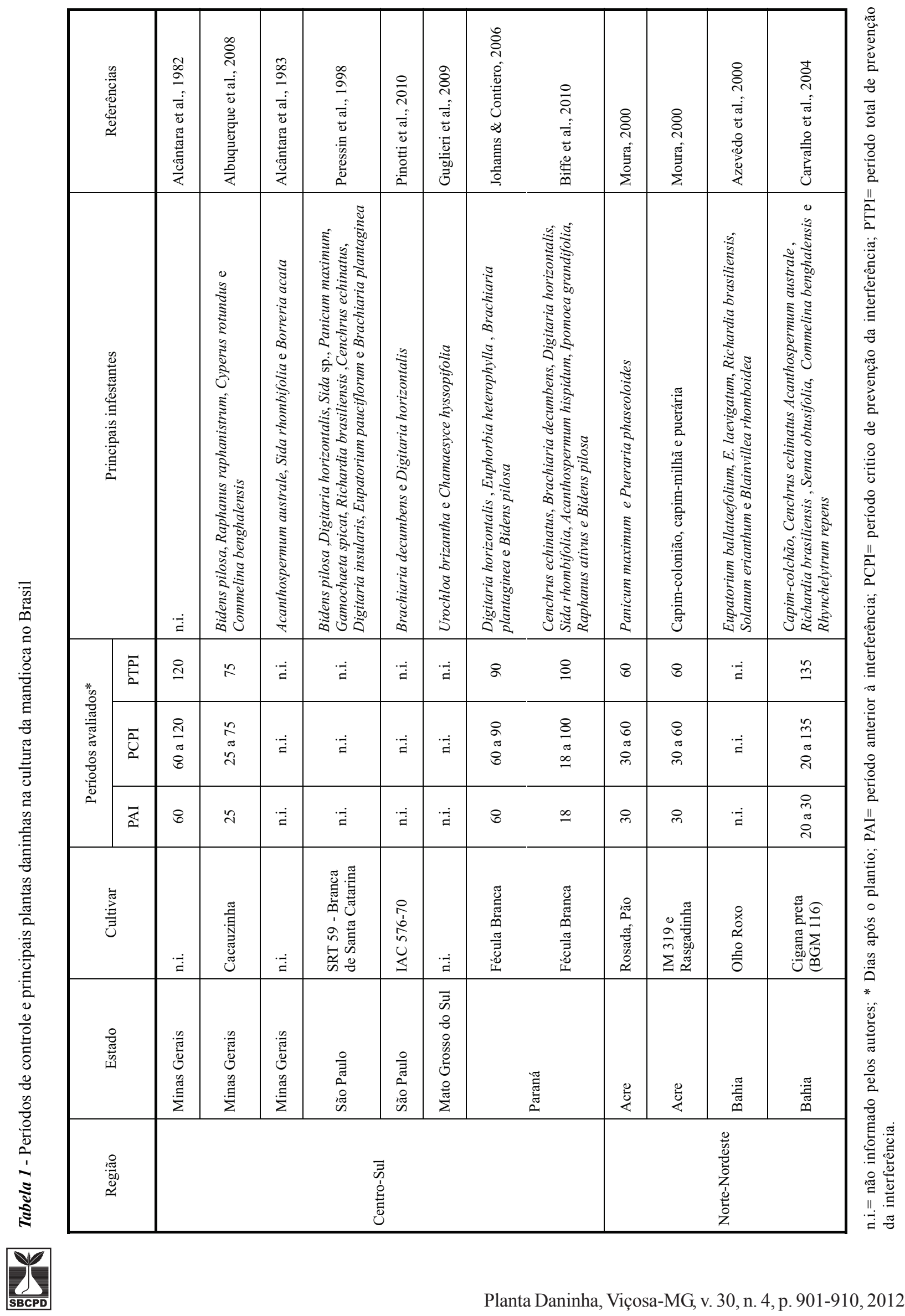


as lavouras são conduzidas no Brasil (época de plantio, cultivares, ciclos de cultivo, espécies infestantes). Nos casos onde é relatada a maior agressividade da interferência das plantas daninhas, as produtividades são próximas a 10\% daquelas obtidas em testemunhas capinadas (Carvalho et al., 1990, 1993; Peresin et al., 1998; Moura, 2000; Johanns \& Contiero, 2006).

Entre os efeitos decorrentes da presença de plantas daninhas, o sombreamento promovido pelas espécies que se desenvolvem mais rapidamente na fase inicial do crescimento da cultura parece ser o mais relevante (Cruz \& Pelacani, 1993). De acordo com esses autores, à medida que a porcentagem de sombreamento na mandioca aumenta, a altura da planta se eleva, sem acréscimo no acúmulo de biomassa caulinar e com redução do índice de área foliar. Esses autores concluem que, com menor exposição à luz, a matéria seca de caule e folhas e o rendimento de raízes da mandioca são comprometidos. Como consequência, o sombreamento promove atraso na formação e diminui a taxa de crescimento das raízes tuberosas.

O manejo inadequado das plantas daninhas reduz o crescimento de parte aérea de plantas de mandioca (Carvalho et al., 1990). Segundo Albuquerque et al. (2008), a produção de parte aérea é de grande importância para a mandiocultura, fornecendo material para propagação e para produção de forragem, além de ser a parte da planta responsável pela absorção de luz e fornecimento de fotoassimilados às raízes. De acordo com Johanns \& Contiero (2006), existe correlação direta entre o período de convivência da cultura com as plantas daninhas e a redução do estande final de plantas e do número de raízes por planta. Entretanto, Moura (2000) e Carvalho et al. (1993) verificaram que os teores de amido e de ácido cianídrico não foram influenciados pela competição.

Além dos efeitos das plantas daninhas sobre o crescimento e desenvolvimento das plantas de mandioca, elas podem atuar como hospedeiras de pragas, atacando a cultura, provocando perdas e até inviabilizando seu cultivo, em determinadas situações. Arnaud et al. (2007) relataram que vírus do gênero
Begomovirus provenientes de plantas daninhas geralmente pertencentes às famílias Malvaceae, Euphorbiaceae e Fabaceae podem ser transmitidos para plantas de mandioca, provocando queda de suas folhas e redução da produtividade de raízes. A buva (Conyza canadensis) é hospedeira da espécie de cochonilha Protortonia navesi, que ataca as raizes de mandioca, podendo ocasionar redução no teor de amido e na produtividade da cultura (Oliveira \& Fontes, 2008). Para esses autores, o controle eficaz das plantas infestantes pode limitar a sobrevivência das pragas, reduzindo a reinfestação de espécies vegetais suscetiveis. Contudo, é importante a promoção de práticas de manejo que viabilizem a presença de inimigos naturais nas infestantes, como estratégia de controle das pragas da cultura.

\section{Periodo crítico de competição das plantas daninhas}

As culturas e as plantas daninhas, sob certas condições, podem crescer juntas por um período sem prejuízo significativo à produção - denominado de período anterior à interferência. Após esse período, a presença das plantas daninhas pode reduzir a produção da cultura. Com o objetivo de sistematizar o estudo da interferência das plantas daninhas que emergem nos ecossistemas agrícolas, Pitelli \& Durigan (1984) estabeleceram três períodos: período total de prevenção à interferência (PTPI), período anterior à interferência (PAI) e período crítico de prevenção a interferência (PCPI), os quais consistem no período de controle da comunidade infestante para otimizar o uso da água, da luz, de nutrientes minerais e do espaço físico. A determinação do período crítico de competição requer métodos específicos, porém clássicos, de pesquisas com plantas daninhas.

Tem-se preconizado que não é necessário manter a cultura no limpo durante todo o seu ciclo para obter as maiores produtividades. Inicialmente (logo após a brotação da cultura), pode existir convivência pacífica entre plantas daninhas e a mandioca. De maneira geral, essa fase coincide com a brotação da maniva e o início da formação das raízes e parte aérea (Peressin \& Carvalho, 2002). Após esse período, 
a planta continua a formação de suas estruturas vegetativas e, mesmo admitindo-se o grande espaçamento entre plantas, a velocidade de cobertura do solo pela diversidade de infestantes promoverá, em curto período de tempo, a interferência. Esse período foi relatado recentemente por Biffe et al.( 2010) como sendo de 82 dias, porém tem variado para diferentes locais e condições (Tabela 1).

Para a mandioca cultivada por um ciclo vegetativo (8 a 12 meses), o controle das plantas daninhas é menos problemático comparado ao cultivo estendido a mais de 20 meses - o mais comumente utilizado -, em que o controle das plantas infestantes, no segundo ano, apesar de menos oneroso, pode tornar-se dificil, pois a cultura já apresenta parte aérea formada, dificultando a entrada na área para o controle (Peressin \& Carvalho, 2002). Nesse caso, entre os dois ciclos, a cultura entra em repouso fisiológico. Essa fase é caracterizada pela queda das folhas e redução da atividade metabólica da planta, e sua duração está em função, principalmente, de condições ambientais. Portanto, é nesse período que se inicia a nova infestação da área com as plantas daninhas. Faz-se, assim, necessário o controle para evitar prováveis prejuízos, bem como para facilitar a colheita. Nesta fase, alguns produtores realizam a poda das plantas de mandioca - prática que, ao mesmo tempo em que facilita o controle por meio da capina, também favorece o surgimento de nova infestação das plantas daninhas.

Com base nas informações apresentadas na Tabela 1, verifica-se que, para a região centro-sul, valores para PAI, PCPI e PTPI variam de 25 a 60,25 a 120 e 75 a 120 dias, respectivamente. Na região norte-nordeste, os valores para PAI variaram de 20 a 30 dias, para PCPI, de 30 a 135 dias, e para PTPI, de 60 a 135 dias. Em estudo realizado na Nigéria, Alabi et al. (2004) recomendam deixar o mandiocal livre da interferência dos 35 aos 77 dias após o plantio. Segundo Melinfonwu (1994), de modo geral, a prevenção deve ser realizada até 84 dias depois do plantio, mas, quando cultivado em consórcio com o milho, esse período poderá ser reduzido para 56 dias. Observa-se que os períodos de controle não são absolutos e variam muito, pois dependem de fatores que afetam o sistema de produção (espaçamento de cultivo, espécies e densidades de plantas daninhas, cultivar utilizado, sistemas de condução da lavoura, regime hídrico, entre outros). Desse modo, os valores de PAI, PCPI e PTPI devem ser analisados considerando-se a localização, a caracterização do ambiente e o sistema de cultivo (ou de produção) da lavoura de mandioca.

\section{Métodos de controle de plantas daninhas}

A escolha do método de controle de plantas daninhas na cultura de mandioca está diretamente relacionada às condições financeiras do agricultor e ao seu acesso a mão de obra e equipamentos. Os métodos utilizados no controle serão mais eficientes se considerados como componente do sistema de produção da cultura.

O método cultural de controle consiste no uso de todas as práticas agrícolas que asseguram o pleno desenvolvimento da cultura, possibilitando vantagens na competição com as plantas daninhas (Silva et al., 2007). Essas práticas consistem em plantio de cultivares adaptados às condições de clima e solo; uso de manivas sadias; profundidade, espaçamentos e arranjos de plantas corretos para os diferentes cultivares; preparo do solo; e adubações de plantio adequadas. Especialmente na cultura da mandioca, o espaçamento e o arranjo de plantas são importantes ferramentas no controle de plantas infestantes. Silva \& Ceretta (1986) afirmam que o sistema de plantio da mandioca em fileiras simples, comparado ao de fileiras duplas, promove o fechamento do solo mais rapidamente, contribuindo para melhor controle das plantas daninhas. Oliveira et al. (1998) também constataram que menores espaçamentos favorecem a cobertura precoce do terreno, diminuindo os custos de controle das infestantes. Pode-se inferir efeito da arquitetura de parte aérea do cultivar sobre o tempo de fechamento das plantas na linha e na entrelinha; quanto maior for o ângulo de ramificação do cultivar em relação à vertical (o que confere porte mais esgalhado), mais rápida será a cobertura do terreno. Ensaio de competição entre plantas daninhas e a cultura da mandioca demonstrou que o cultivar Periquita, por apresentar caule com três ramificações (tricotômico) e ser uma planta compacta (arquitetura de planta "moderna"),

Planta Daninha, Viçosa-MG, v. 30, n. 4, p. 901-910, 2012 
proporcionou maior cobertura foliar e ocupação uniforme da área, o que pode levar, quando em espaçamentos menores, à redução da disponibilidade de radiação solar para fotossíntese das espécies infestantes. Contudo, conforme Moura (2000), o hábito de ramificação de plantas de mandioca não confere vantagens no que se refere à produtividade de raízes e à competição com plantas daninhas. Entretanto, a definição do espaçamento e do arranjo espacial deve considerar o cultivar a ser utilizado, para que os fatores de produção não sejam afetados.

No método mecânico, o preparo periódico do solo promove o controle de plantas daninhas por meio do efeito mecânico de quebra, do arranque e da exposição das estruturas das plantas à secagem pelo sol, fato que promove a redução do banco de sementes do solo (Silva et al., 2006). Segundo Otsubo et al. (2008), o plantio direto ou o cultivo mínimo associado ao uso de plantas de cobertura do solo pode aumentar a sustentabilidade dos sistemas de produção de mandioca e auxiliar no controle das daninhas, pois oferece melhores condições ao crescimento e desenvolvimento da cultura, favorecendo-a na competição com as invasoras. O não revolvimento do solo permite maior espaço de tempo útil para o plantio, que deve ser realizado quando o solo apresenta teor de água suficiente para a brotação das manivas (Gabriel Filho et al., 2003). Almeida (1991) relata que a cobertura morta, principalmente de Avena strigosa, exerce efeitos alelopáticos sobre várias espécies de plantas daninhas, reduzindo o crescimento e a interferência dessas espécies sobre a cultura principal.

A melhora da fertilidade do solo promove efeitos diretos no desenvolvimento da mandioca. Carvalho et al. (2007) ressaltam a importância da adubação fosfatada para melhor resposta da cultura em crescimento da parte aérea e acúmulo de biomassa nas raízes. Do mesmo modo, Osson (2010) recomenda a aplicação de $60 \mathrm{t} \mathrm{ha}^{-1}$ de torta de filtro, por permitir o maior desenvolvimento da cultura e cobertura do solo, contribuindo para o controle das plantas daninhas. Amanullah et al. (2006) sugerem que a compostagem de esterco de galinha (10 t ha-1) aumenta a produtividade e o indice de área foliar da cultura, sombreando as plantas daninhas e inibindo seu crescimento.
O estabelecimento de consórcios entre culturas de valor econômico e adubos verdes é outra medida cultural que pode reduzir os gastos com controle de plantas daninhas. Além disso, pode promover renda adicional ao produtor, melhor cobertura do solo, aporte de nutrientes e matéria orgânica, distribuição da força de trabalho e manutenção do equilíbrio biológico no agroecossistema (Devide et al., 2009). Entre as espécies com potencial de consórcio com mandioca, destacam-se o feijão-guandu (Cajanus cajan), o girassol (Helianthus annus) e o feijão-caupi (Vigna unguiculata) (Silva et al., 2009). Além dessas espécies, outras, como o feijão-comum (Phaseolus vulgaris), omilho (Zea mays), o amendoim (Arachishypogaea), a soja (Glycine max) e o quiabo (Abelmoschus esculentus), são cultivadas em consórcio com a cultura da mandioca e na população, e arranjos corretos não causam decréscimo na produção desta (Tsay et al., 1987; Mattos et al., 1990, 1994; Olasantan \& Bello, 2004; Schons et al., 2009). O consórcio pode ser efetuado com a cultura da mandioca plantada em fileiras simples ou duplas; estas últimas apresenta vantagens, devido ao melhor uso dos espaços livres que existem entre cada fileira dupla e mínima redução da produtividade das culturas (Mattos et al., 2000). Schons et al. (2009) recomendam o arranjo de mandioca em fileiras duplas no espaçamento de $1,6 \times 0,5 \times 0,6 \mathrm{~m}$, com uma fileira de milho no espaçamento de $0,8 \times 0,2 \mathrm{~m}$ ou duas fileiras no espaçamento de 0,4 x 0,4 m dispostas entre as fileiras duplas de mandioca, com semeadura na emergência da mandioca.

A mandioca apresenta porte médio entre 0,6 e 3 m (Vidigal Filho et al., 2000), e a disposição das linhas de plantio pode promover até $100 \%$ de sombreamento, considerando-se a radiação direta ao solo. Cultivares de porte mais baixo, como Fibra, Verdinha e Espeto, poderão permitir mais passagem de luz caso o direcionamento das linhas acompanhe o caminhamento do sol. Nessas situações é interessante o consórcio, uma vez que a entrada de luz na entrelinha possibilitará melhor desenvolvimento de outras plantas. Entretanto, sabe-se, na prática, que o direcionamento de linhas está normalmente em função da declividade do terreno.

Em diversas regiões do Brasil, a capina manual com enxada ainda é o método de 
controle de plantas daninhas mais utilizado nos mandiocais, principalmente onde se pratica a agricultura de subsistência. No entanto, devido à escassez de mão de obra, esse tipo de controle tem sido substituído. Conforme Alves \& Silva (2003), a participação da mão de obra em capina manual representava $30 \%$ do custo total de produção de mandioca no Estado de São Paulo. Segundo Silva \& Chabaribery (2006), para a capina mecânica e manual, ela representa cerca de $25,7 \%$ do custo operacional total da cultura. Moura (2000) considera suficiente para o controle das plantas daninhas nos mandiocais duas capinas, aos 30 e 60 dias após o plantio, no Estado do Acre. O mesmo número de capinas é suficiente para controlar as plantas daninhas na Nigéria, onde, no entanto, o controle químico mostrou-se mais econômico quando comparado ao custo das capinas (Akobundu, 1980; Melifonwu, 1994). Uma alternativa para diminuir os custos é a redução do número de capinas, através da associação entre os métodos de controle.

O método químico de controle das plantas daninhas caracteriza-se por permitir a intervenção em grandes áreas com pouca dependência de mão de obra e rapidez na aplicação. A resposta da mandioca à aplicação de herbicidas varia desde a total seletividade para alguns produtos até o completo comprometimento da produção por causa da intoxicação provocada à cultura (Alcântara \& Lima, 1982; Oliveira Jr., 1994). Atualmente, existem registrados no mercado brasileiro (Brasil, 2011) 12 princípios ativos com ação herbicida para a cultura da mandioca, sendo apenas três diferentes mecanismos de ação (Tabela 2). Entre esses herbicidas recomendados para a cultura da mandioca, o clomazone e o isoxaflutole são inibidores da síntese de carotenoide com eficiência em espécies gramineas anuais e perenes e de folhas largas. As doses recomendadas devem ser diferenciadas para cada tipo de solo (Oliveira Jr et al., 2001). Outro grupo de herbicida que possui representante com registro para uso na cultura da mandioca são os inibidores do fotossistema II (ametryn e metribuzin), os quais são recomendados para uso antes da brotação das manivas e emergência das plantas daninhas (Brasil, 2011), para controle de folha larga. Misturas de ametryn + clomazone e ametryn + diuron, ambas aplicadas em pós-emergência das plantas daninhas e quando a mandioca estava com 5 a $10 \%$ das brotações emergidas, foram seletivas para a cultura e eficientes no controle de Bidens pilosa, Commelina benghalensis, Raphanus sativus e Sida rhombifolia (Oliveira Jr. et al., 2001). Atualmente existe apenas um herbicida registrado para uso em pós-emergência para a mandioca no Brasil: o cletodim. Este é recomendado para o controle de gramíneas anuais e perenes, pois apresenta pouca ou nenhuma atividade sobre as plantas daninhas de folhas largas e ciperáceas (Brasil, 2011).

Talvez por falta de interesse das indústrias de defensivos, há diversas moléculas de herbicidas que possibilitaram resultados de pesquisa satisfatórios no controle das plantas

Tabela 2 - Herbicidas registrados para a cultura da mandioca (Brasil, 2011)

\begin{tabular}{|c|c|c|c|}
\hline Marca comercial & Ingrediente ativo (grupo químico) & Dosagem & Época de aplicação \\
\hline $\begin{array}{l}\text { Ametrex WG } \\
\text { Clomanex } 500 \text { EC }\end{array}$ & $\begin{array}{l}\text { ametryn (triazina) } \\
\text { clomazone (isoxazolidinona) }\end{array}$ & $\begin{array}{l}2,0-3,0 \mathrm{~L} \mathrm{ha}^{-1} \\
1,6-2,0 \mathrm{~L} \mathrm{ha}^{-1}\end{array}$ & $\begin{array}{l}\text { Pré-emergente } \\
\text { Pré-emergente }\end{array}$ \\
\hline Clomazone 500 EC FMC & clomazone (isoxazolidinona) & $1,6-2,0 \mathrm{~L} \mathrm{ha}^{-1}$ & Pré-emergente \\
\hline Gamit & clomazone (isoxazolidinona) & $1,6-2,0 \mathrm{~L} \mathrm{ha}^{-1}$ & Pré-emergente \\
\hline Gamit $360 \mathrm{CS}$ & clomazone (isoxazolidinona) & $1,7-2,8 \mathrm{~L} \mathrm{ha}^{-1}$ & Pré-emergente \\
\hline $\begin{array}{l}\text { Herbipak WG } \\
\text { Lord }\end{array}$ & $\begin{array}{l}\text { ametryn (triazina) } \\
\text { cletodim (oxima ciclo-hexanodiona) }\end{array}$ & $\begin{array}{c}2,0-3,0 \mathrm{~L} \mathrm{ha}^{-1} \\
0,35-0,45 \mathrm{~L} \mathrm{ha}^{-1}\end{array}$ & $\begin{array}{l}\text { Pré-emergente } \\
\text { Pós-emergente }\end{array}$ \\
\hline Magister & clomazone (isoxazolidinona) & $1,6-2,0 \mathrm{~L} \mathrm{ha}^{-1}$ & Pré-emergente \\
\hline Provence $750 \mathrm{WG}$ & isoxaflutole (isoxazol) & $100-125 \mathrm{~g} \mathrm{ha}^{-1}$ & Pré-emergente \\
\hline Select 240 EC & cletodim (oxima ciclo-hexanodiona) & $0,35-0,45 \mathrm{~L} \mathrm{ha}^{-1}$ & Pós-emergente \\
\hline $\begin{array}{l}\text { Sencor } 480 \\
\text { Sinerge EC }\end{array}$ & $\begin{array}{l}\text { metribuzin (triazinona) } \\
\text { ametryn (triazina) + clomazone } \\
\text { (isoxazolidinona) }\end{array}$ & $\begin{array}{c}0,75-1,0 \mathrm{~L} \mathrm{ha}^{-1} \\
3-5 \mathrm{~L} \mathrm{ha}^{-1}\end{array}$ & $\begin{array}{l}\text { Pré-emergente } \\
\text { Pré-emergente }\end{array}$ \\
\hline
\end{tabular}


daninhas, sendo seletivos para a mandioca, porém ainda estão sem registro. Entre esses produtos estão o acetolachlor, alachlor, flumioxazin, metolachlor e trifluralin para aplicação em pré-emergência (Oliveira Jr. et al., 2001). Biffe et al. (2007) relatam que o herbicida diuron, aplicado em pré-emergência total ou em pós-emergência em jato dirigido, proporciona controle satisfatório para muitas espécies de plantas daninhas, gramíneas e dicotiledôneas. Para aplicação em pós emergência, o aciclofen, fluazifop-p-butil e mesotrione apresentaram seletividade a mandioca, podendo ser incluídos em programas de manejo de plantas daninhas (Oliveira Jr. et al., 2001; Silva et al., 2011; Silveira et al., 2012 ).

Além da aplicação em pós-emergência de herbicidas seletivos, podem-se também utilizar moléculas não seletivas, seja em jato dirigido ou aplicação logo após a poda da mandioca. Recomendam-se os herbicidas à base de glyphosate em aplicações dirigidas, evitando atingir as folhas da cultura, e quando a mandioca esteja com aproximadamente cinco meses e com 30 a $40 \mathrm{~cm}$ de haste em relação ao solo. Pode-se acrescentar ainda um herbicida préemergente, com efeito residual, para aumentar o período de controle (Silva et al., 2009).

De modo geral, o manejo integrado de plantas daninhas tem se mostrado a melhor ferramenta para o controle na cultura da mandioca. Medidas como utilização da capina ou emprego direto de herbicidas podem ser consideradas como de curta duração, sendo responsáveis por controle apenas temporário, havendo necessidade de novas intervenções a cada novo ciclo de infestação. O emprego de práticas como o consorciamento e o plantio direto auxilia no controle eficiente, quando combinado com capina e controle químico. Assim, torna-se importante para o produtor utilizar-se dos diversos métodos de controle discutidos anteriormente, para que essa prática seja mais econômica e menos danosa ao ambiente do que o uso exclusivo de herbicidas.

\section{CONSIDERAÇÕES FINAIS}

Cultivares de mandioca estão sendo lançados a cada ano, com novas características de arquitetura, de espaçamento de plantio e de ciclo. O comportamento desses cultivares em relação à competição com as plantas daninhas deve ser mais bem estudado pelos pesquisadores, a fim de auxiliar o produtor na escolha do momento e do método correto para o controle. Também é necessário desenvolver novos estudos sobre a eficiência dos métodos de controle, além de avaliar o custo destes para o produtor de mandioca. Estudos sobre o nível de dano econômico das principais plantas infestantes dos mandiocais auxiliariam na escolha do momento para a prevenção da interferência. Como foram discutidos anteriormente, os resultados sobre período de controle e as principais infestantes são variados, de acordo com as particularidades de cada local de cultivo, tornando-se necessário esse tipo de estudo nas principais regiões produtoras.

O controle cultural mostra-se eficiente no manejo de plantas daninhas, principalmente com a utilização dos cultivos consorciados. Diversos estudos já comprovaram a eficiência da mandioca nesse sistema, além de otimizar o uso da área e proporcionar fonte de renda ao produtor. No entanto, estudos sobre a integração mandioca-pecuária e sobre a utilização de herbicidas nesse sistema, como também no consorciado, não existem ou são incipientes, sendo importante o desenvolvimento de pesquisas nessas áreas. Por ser em muitas regiões cultura de subsistência, estratégias como o estabelecimento de consórcios com outras culturas e adubos verdes ajudam no controle. No entanto, são poucas as informações sobre o número de intervenções necessárias para o controle nesse tipo de sistema.

Há necessidade de mais estudos sobre métodos integrados de controle de plantas daninhas envolvendo herbicidas seletivos para a cultura da mandioca, principalmente para aplicação em pós-emergência da cultura, devido ao longo ciclo e à reinfestação da área pelas daninhas. O MIPD mostra-se como a estratégia de manejo mais eficiente para o controle, por promover condição adequada para que a mandioca tenha vantagem sobre a espécie infestante, além de otimizar o sistema de manejo da cultura.

\section{AGRADECIMENTOS}

À Coordenação de Aperfeiçoamento de Pessoal de Nivel Superior (Capes), ao Conselho 
Nacional de Desenvolvimento Científico e Tecnológico (CNPq) e à Fundação de Amparo à Pesquisa do Estado de Minas Gerais (FAPEMIG), pelo apoio na execução deste trabalho.

\section{LITERATURA CITADA}

ALABI, B. S. et al. Manual control of thorny mimosa (Mimosa invisa) in cassava (Manihot esculenta). Weed Technol., v. 18, n. 1, p. 77-82, 2004.

ALBUQUERQUE, J. A. A. et al. Interferência de plantas daninhas sobre a produtividade da mandioca (Manihot esculenta). Planta Daninha, v. 26, n. 2, p. 279-289, 2008.

ALCÂNTARA, E. N. et al. Determinação do período crítico de competição das plantas daninhas com a cultura da mandioca (Manihot esculenta Crantz). Belo Horizonte: EPAMIG, 1983. p. 147-149.

ALCÂNTARA, E. N.; LIMA, P. C. Efeito de doses de herbicida para a cultura da mandioca (Manihot esculenta Crantz). In: EPAMIG. Projeto Mandioca, relatório 76/79. 1982. Belo Horizonte: EPAMIG, 1982. p. 130-135.

ALMEIDA, F. S. Controle de plantas daninhas em plantio direto. Londrina: IAPAR, 1991. 34 p.

ALVES, A.A.C.; SILVA, A.F. Embrapa mandioca e fruticultura. Cultivo da mandioca para a Região SemiÁrida. Disponível em: <http://sistemasdeproducao .cnptia.embrapa.br/FontesHTML/Mandioca/ mandioca_semiarido/coeficientestecnicos.htm.>, 2003. Acesso em: 5 maio 2011.

AKOBUNDU, O. Weed control in cassava cultivation in the subhumid tropics. Inter. J. Pest Manag., v. 26, n. 4, p. 420-426, 1980.

AMANULLAH, M. M. et al. Intercropping and organic manures on the growth and yield of cassava (Manihot esculenta Crantz.). Res. J. Agric. Biol. Sci., v. 2, n. 5, p. 183-189, 2006.

ARNAUD, L. S. E. P. et al. Predominância de begomovírus em tomateiros na região produtora da Ibiapaba, Ceará, e sua detecção natural em plantas daninhas. Fitopatol. Bras., v. 32, n. 3, p. 241-246, 2007.

AZEVÊDO, C. L. L. et al. Levantamento de plantas daninhas na cultura da mandioca, em um ecossistema semi-árido do Estado da Bahia. Magistra, v. 12, n. 1/2, p.41-49, 2000.

BIFFE, D. F. et al. Avaliação do herbicida diuron em préemergência no controle de seis plantas daninhas na cultura de Manihot esculenta. R. Raízes Amidos Trop., v. 3, n. 1, p. 1-4, 2007 .
BIFFE, D. F. et al. Período de interferência de plantas daninhas em mandioca (Manihot esculenta) no noroeste do Paraná. Planta Daninha, v. 28, n. 3, p. 471-478, 2010 .

CARVALHO, J. E. B. et al. Período crítico de competição das plantas daninhas com a cultura da mandioca em três ecossistemas do Nordeste brasileiro. R. Bras. Mandioca, v. 9, n. 1, p. $29-40,1990$.

CARVALHO, J. E. B. et al. Período crítico de competição das plantas daninhas com a cultura da mandioca em um ecossistema do Nordeste brasileiro. R. Bras. Mandioca, v. 12, n. 1, p. 85-93, 1993.

CARVAlHO, J. E. B. et al. Período de controle de plantas infestantes na cultura da mandioca no Estado da Bahia. Cruz das Almas: Embrapa, 2004. 7 p. (Comunicado Técnico, 109).

CARVALHO, F. M. et al. Manejo do solo em cultivo com mandioca em treze municípios da região sudeste da Bahia. Ci. Agrotec., v. 31, n. 2, p. 378-384, 2007.

CRUZ, J. L.; PELACANI, R. Fisiologia da mandioca. In: CURSO NACIONAL DE MANDIOCA, 8., 1993, Cruz das Almas. Anais... Cruz das Almas: Embrapa/CNPMF, 1993. $38 \mathrm{p}$.

DEVIDE, A. C. P. et al. Produtividade de raízes de mandioca consorciada com milho e caupi em sistema orgânico.

Bragantia, v. 68, n. 1, p. 145-153, 2009.

GABRIEL FILHO, A. et al. Profundidade e espaçamento da mandioca no plantio direto na palha. Ci. Rural, v. 33, n. 3, p. 461-467, 2003.

GUGLIERI, A. et al. Fitossociologia de plantas espontâneas em um mandiocal implantado em pastagem cultivada em Mato Grosso do Sul, Brasil. R. Ci. Agr., v. 51, n. 1, p. 127-141, 2009.

INSTITUTO BRASILEIRO DE GEOGRAFIA E ESTATÍSTICA - IBGE. Sétima previsão da safra 2011/2012. Disponível em: <http://www1.ibge.gov.br/home/presidencia/ noticias/noticia_visualiza.php?id_noticia $=1798 \&$ id_pagina =1>. Acesso em: 10 abr. 2011.

JOHANNS, O.; CONTIERO R. Efeitos de diferentes períodos de controle e convivência de plantas daninhas com a cultura da mandioca. R. Ci. Agron., v. 37, n. 3, p. 326-331, 2006.

BRASIL. Ministério da Agricultura, Pecuária e Abastecimento. Coordenação-Geral de Agrotóxicos e Afins. Disponível em: < http://extranet.agricultura.gov.br/ agrofit_cons/principal_agrofit_cons. ->. Acesso em: 1ำ mar. 2011.

Planta Daninha, Viçosa-MG, v. 30, n. 4, p. 901-910, 2012 
MATTOS, P. L. P.; SOUZA, A. S.; CALDAS, R. C. Consorciação de mandioca plantada em fileiras duplas com feijão. R. Bras. Mandioca, v. 9, n. 1/2, p. 83-90, 1990.

MATTOS, P. L. P.; SOUZA, A. S.; CALDAS, R. C. Cultivo da mandioca e amendoim em sistemas consorciado e monocultivo. R. Bras. Mandioca, v. 13. n. 1, p. 29-45, 1994.

MATTOS, P. L. P. Consorciação. In: MATTOS, P. L. P.; GOMES, J. C. (Coord.). O cultivo da mandioca. Cruz das Almas: Embrapa Mandioca e Fruticultura, 2000. p. 33-41. (Circular Técnica, 37).

MELIFONWU, A. A. Weeds and their control in cassava. Afr. Crop Sci. J., v. 2, n. 4, p. 519-530, 1994.

MOURA, G. M. Interferência de plantas daninhas na cultura da mandioca (Manihot esculenta Crantz) no Estado do Acre. Planta Daninha, v. 18, n. 3, p. 451-456, 2000.

NASSAR, N. M. A. Mandioca: opção contra a fome.Estudos e lições no Brasil e no mundo. Ci. Hoje, v. 39, n. 231, p. 30-36, 2006.

OLASANTAN, F. O.; BELLO N. J. Optimum sowing dates for okra (Abelmoschus esculentus) in monoculture and mixture with cassava (Manihot esculenta) during the rainy season in the south-west of Nigeria. J. Agric. Sci., v. 1, n. 1, p. 49-58, 2004.

OLIVEIRA, C. M.; FONTES, J. R. A. Weeds as hosts for new crop pests: the case of Protortonia navesi (Hemiptera: Monophlebidae) on cassava in Brazil. Weed Res., v. 48, n. 3 , p. $197-200,2008$.

OLIVEIRA JR., R. S. Seletividade e eficiência de trifluralin e diuron aplicados em diferentes formas na cultura da mandioca (Manihot esculenta Crantz). R. Unimar, v. 16, n. 2, p. 317-325, 1994.

OLIVEIRA JR., R. S. et al. Tolerância de cinco cultivares de mandioca (Manihot esculenta) a herbicidas. Planta Daninha, v. 19, n. 1 , p. $119-125,2001$.

OLIVEIRA, E. A. M. et al. Efeito do espaçamento entre plantas e da arquitetura varietal no comportamento vegetativo e produtivo da mandioca. Sci. Agric., v. 55, n. 2, p. 269-275, 1998.

OSSOM, E. M. Effects of filter cake fertilization on weed infestation, disease incidence and tuber yield of cassava (Manihot esculenta) in Swaziland. Inter. J. Agric. Biol., v. 12, n. 1, p. 45-50, 2010.

OTSUBO, A. A. et al. Sistemas de preparo do solo, plantas de cobertura e produtividade da cultura da mandioca. Pesq. Agropec. Bras., v. 43, n. 3, p. 327-332, 2008.
PERESSIN, V. A. et al. Acúmulo de matéria seca na presença e na ausência de plantas infestantes no cultivar de mandioca SRT 59 - Branca de Santa Catarina. Bragantia, v. 57, n. 1, p. 135-148, 1998.

PERESSIN, V. A.; CARVALHO, J. E. B. Manejo integrado de plantas daninhas em mandioca. In: Marney Pascoli Cereda. (Org.). Cultura de Tuberosas Amiláceas Latino Americanas. São Paulo: Fundação Cargill, 2002. v. 2, p. 302-349.

PINOTTI E. B. et al. Levantamento florístico de plantas daninhas na cultura da mandioca no município de Pompéia SP. R. Raízes Amidos Trop., v. 6, n. 1, p. 120-125, 2010.

PITELLI, R. A.; DURIGAN, J. C. Terminologia para períodos de convivência e de controle das plantas daninhas em culturas anuais e bianuais. In: CONGRESSO DE LA ASSOCIACION LATINO AMERICANA DE MALEZAS, 18., 1884, Belo Horizonte. Resumos... Belo Horizonte: Asociacion Latinoamericana de Malezas, 1984. p. 37-38.

SCHONS, A. et al. Arranjos de plantas de mandioca e milho em cultivo solteiro e consorciado: Crescimento, desenvolvimento e produtividade. Bragantia, v. 68 , n. 1, p. $155-167,2009$.

SILVA, J. R.; CHABARIBERY, D. Coeficientes técnicos e custo de produção da mandioca para mesa na região de MogiMirim, Estado de São Paulo. Inf. Econ., v. 36, n. 1, p. 26-32, 2006.

SILVA, A. A.; SILVA, J. F. (Eds.). Tópicos em manejo de plantas daninhas. Viçosa, MG: Universidade Federal de Viçosa, 2007. p. 17-62.

SILVA, A. F. et al. Produção de diferentes cultivares de mandioca em sistema agroecológico. R. Bras. Eng. Agríc. Amb., v. 13, n. 1, p. 33-38, 2009.

SILVA, P. R. F.; CERETTA, C. A. Sistemas de cultivo de mandioca. Monocultivo em fileiras simples e duplas. R. Bras. Mandioca, v. 5, n. 2, p. 55-63, 1986.

SILVA, D. V. et al. Tolerância de cultivares de mandioca aos herbicidas fomesafen e fluazifop-p-butil. R. Bras.

Herbicidas, v. 10, n. 3, p. 219-231, 2011.

SILVEIRA, H. M. et al. Sensibilidade de cultivares de mandioca ao herbicida mesotrione. Revista Bras. Herbicidas, v. 11, n. 1, p. 24-31, 2011.

TSAY, J. S. et al. The response of cassava (Manihot esculenta) to spatial arrangement and to soybean intercrop. Field Crop Res., v. 16, n. 1, p. 19-31, 1987.

VIDIGAL FILHO, P. S. et al. Avaliação de cultivares de mandioca na região noroeste do Paraná. Bragantia, v. 59, n. 1, p. $69-75,2000$. 